Küçük yaş

grubundaki

çocuklarda dental

rahatsızlık anketi'nin

Türkçe güvenirliği ve

geçerliğinin

değerlendirilmesi:

Pilot çalışma

\section{Evaluation of Turkish validity and reliability of dental iscomfort questionnaire on young children: A pilot study}

Dt. Güler Burcu Senirkentli

Başkent Üniversitesi, Diş Hekimliği Fakültesi, Çocuk Diş Hekimliği A.D., Ankara

Orcid ID: 0000-0003-4918-5504

Doç. Dr. Resmiye Ebru Tirali

Başkent Üniversitesi, Diş Hekimliği Fakültesi, Çocuk Diş Hekimliği A.D., Ankara

Orcid ID: 0000-0001-6487-3984

Geliş tarihi: 22 Haziran 2018

Kabul tarihi: 23 Ocak 2019

doi: 10.5505/yeditepe.2019.94899

\section{Yazışma adresi:}

Dt. Güler Burcu Senirkentli

Başkent Üniversitesi, Diş Hekimliği Fakültesi,

Cocuk Diş Hekimliği A.D.

11. Sokak No:26 Bahçelievler, Çankaya, Ankara

Telefon: 03122151336

Faks: 03122122962

E-posta: gburcubostanci@yahoo.com
ÖZET

Amaç: Bu çalışmada okul öncesi çocuklarda dental ağrının değerlendirilmesi amacı ile geliştirilen Dental Rahatsızlık Anketi (DRA)'nin Türkçe uyarlamasının geçerliği ve güvenirliğinin değerlendi-rilmesi amaçlanmıştır.

Gereç ve Yöntem: Çalışmaya Başkent Üniversitesi Diş Hekimliği Fakültesi Çocuk Diş Hekimliği Anabilim Dalı'na Ocak 2017- Ekim 2017 tarihleri arasında başvuran 2-6 (ortalama 3,84 ) yaşları a-rasındaki ASAI risk grubunda yer alan 120 hasta dahil edilmiştir. Kültürel olarak uyarlanmış sorular ebeveynler tarafından herhangi bir dental müdahale yapılmadan önce cevaplanmıştır. Ölçeğinin güvenilirlik çalışması kapsamınd iç tutarlıık Cronbach alfa katsayısı, test-tekrar test tutarııı̆ı Sınıf İçi Korelasyon Katsayısı (SKK) ile değerlendirilmişsir. DRA'nın Türkçe versiyonunun geçerliliği ile, toplam DRA puanı ile dmft skoru arasındaki ilişki Spearman korelasyon katsayısı ile incelenmiştir.

Bulgular: DRA anketi Türkçe versiyonu ile dmft indeksi arasında istatistiksel olarak anlamlı bir fark bulunmazken $p>0,05$ aralarında pozitif korelasyon olduğu görülmüştür $(r=0,145)$. Cronbach's Alpha katsayısı ile güvenirlik hesaplaması sonucu güvenirlik 0,799 ve iç tutarlılık analizi yapıldığında iç tutaralık değeri 0,813 olarak bulunmuştur. Yapılan test-tekrar test uyum katsayısı 0.988 bulun-muştur $(p<0,001)$. DRA Türkçe versiyonunda kız $(7,78 \pm 5,16)$ ve erkek çocukların $(8,67 \pm 5,05)$ total DRA puanları arasında anlamlı bir fark bulunmamıştır ( $p>0,05)$. DRA toplam puanının cinsiyete göre değişmediği ve DRA Türkçe versiyonu ile yaş arasında zıt yönlü bir ilişki olduğu görülmüştür.

Sonuç: DRA'nin Türkçe versiyonunun geçerli ve güvenilir bir ölçek olduğuna karar verilmiştir.

Anahtar kelimeler: Ağrı değerlendirme, çocuklarda dental ağrı, dental rahatsızlık anketi.

SUMMARY

Aim: In this study, it was aimed to evaluate the reliability and validity of the Turkish version of the Dental Discomfort Questionnaire (DRA) developed for evaluating dental pain in preschool children.

Materials and methods: The study included 120 patients in the ASAl risk group between 2-6 (me-an 3.84) years, who applied to Başkent University School of Dentistry Department of Pediatric Dentistry between January 2017 and October 2017. Culturally adapted questions were answered by parents prior to any dental intervention. In the reliability study of the scale, internal consistency was assessed by Cronbach's alpha coefficient and test-retest consistency was assessed by Intraclass Cor-relation Coefficient. The validity of the Turkish version of the DRA investigated by Spearman cor-relation coefficient between total score and $\mathrm{dmft} / \mathrm{dft}$ score.

Results: Although there was no statistical significance between the Turkish version of the DRA questionnaire and the DMFT/dft index ( $p=0.111)$, it was found that there was a positive correlati-on $(r=0.145)$. When the reliability and internal 
consistency analysis were performed with Cron-bach's Alpha coefficient, internal consistency value was found as 0.813 . Test-retest consistency co-efficient was 0.988 ( $p$ $<0.001)$. There was no significant difference between the DRA scores of girls $(7.78 \pm 5.16)$ and boys $(8.67 \pm 5.05)$ in Turkish version of DRA ( $p>0,05)$. DRA total score does not change according to sex. DRA was found to have an opposite relationship between the Turkish ver-sion and age. Conclusion: The Turkish version of DRA was found to be a measurement tool with statistically high validity and reliability indices.

Keywords: Dental Discomfort Questionnaire, Dental pain in children, pain assessment methods.

\section{Giriş}

Ağrı araştırmacılar ve klinisyenler tarafından hala tam olarak anlaşılamamış olan kompleks, biyolojik ve davranışsal bir kavramdır.' Diş hekimliğinde ağrı konusu oldukça önemlidir. Akut yada kronik diş ağrısının çocuklarda düzensiz beslenme ve uyku alıskanlıklarına neden olduğu ve ruhsal durum-larını olumsuz yönde etkiledikleri görülmüştür. Dental ağrının tespiti ve erken tanımlanması koru-yucu ve restoratif diş hekimliğinde büyük önem taşımaktadır. Doğru tanı, teşhis ve tedavi planlama aşamalarının her birinde ağrı bir yol gösterici niteliğindedir. Diş ağrısının tanımlanması ve çürüklerin erken evrede saptanması ile; dental anksiyete gelişimi,daha invaziv veya genel anestezi altında den-tal tedavi intiyacını azaltabilir. ${ }^{2}$

Ağrı deneyimi özel ve sübjektiftir, dolayısı ile başkaları tarafından direkt anlaşılamaz. Bu yüzden kişisel beyan ağrı değerlendirmesi için tercih edilen bir yöntemdir. Bununla birlikte yaş ve gelişimsel durumları nedeni ile sınırlı sözel yeteneğe sahip olan küçük çocuklarda ağrıyı tanımlamak ve değer-lendirmek her zaman mümkün değildir. ${ }^{3}$ Bu nedenle küçük çocuklarda ağrı değerlendirilmesinde sözsüz, davranışsal teknikler gibi dolaylı ağıı değerlendirme yollarına başvurulmaktadır. Çocuğun yaşına ve iletişim yeteneklerine göre kullanılabilecek geçerli ve klinik anlamda hassas bir çok değer-lendirme aracı mevcuttur., ${ }^{3,4}$ Dental Rahatsızlık Anketi-DRA (Dental Discomfort Questionnaire-DDQ) küçük çocuklarda (5 yaş ve altı) diş ağrısı ve ağrı ile ilgili davranışların (yemek yerken rahatsızıı, uyku düzensizliği ve diğer ağrıya bağlı davranışlar) gözlemlenerek skorlanmasını amaçlayan bir değerlendirme aracıdır. ${ }^{5}$ DRA farklı dillere çevrilerek geçerlilik ve güvenilirliği test edilmiştir. Başka dillere yapılan ölçek çevirile-rinde, çevirinin hedef topluluğun sosyoekonomik ve kültürel yapısına uyum sağlaması, kelime ve kelime gruplarının hedef kitle tarafından anlaşııması ve orijinali ile yüzde yüz eşdeğer olması amacı ile kültürel adaptasyon uyarlaması yapılmalıdır. ${ }^{6}$

Bu çalışmada okul öncesi dönemdeki çocuklarda dental ağrının değerlendirilmesi amacıyla oluştu-rulan Dental Rahatsızlık Anketi'nin kültürel adaptasyonunun sağlan- ması için Türkçe güvenirliği ve geçerliğinin değerlendirilmesi amaçlanmıştır.

\section{GEREÇ VE YÖNTEM}

Başkent Üniversitesi Diş Hekimliği Fakültesi Çocuk Diş Hekimliği Anabilim Dalı́na Ocak 2017- Ekim 2017 tarihleri arasında dental ağrı ile başvuran 2-6 yaş arasındaki ASA1 risk grubunda yer alan hastalar çalışmaya dahil edilmiştir. Bu çalışma Başkent Üniversitesi Araştıma ve Etik Kurulu tarafından onaylanmıştır (Proje no: D-KA16/20).

Örneklem genişliğinin belirlenmesi amacı ile yapılan power analizi sonucunda anket çalışmasının dil geçerliğinin değerlendirilmesi için Türkçe'ye çevrilen DRA anketi 30 kişilik hasta grubuna uygulan-mış; anketin geçerlilik ve güvenilirliğinin değerlendirilmesinde ise \%95 güvenilirlik ve \%80 güç ile 120 kişi çalışmaya dahil edilmiştir.

Çalışmaya dahil olma özelliklerini taşıyan hasta velileri çalışma hakkında bilgilendirilmiş, çalışmanın riskleri ve yararları anlatılmış, bunun sonucunda onamları alınmıştır. Çalışmaya katılmayı kabul eden katıımcıların ayrıntılı medikal ve dental hikayeleri alındıktan sonra, klinik ve radyografik muayene-leri yapılmıştır. Bu kısıtlamalar dahilinde, ASA1 risk grubu dışındaki ve çalışmaya katılmak iste-meyen hastalar çalışma dışı bırakılmıştır. Çalışmaya katılan denek sayısı 120 'dir.

Farklı bir dilden Türkçe'ye çevirisi yapılan DRA anketinin orijinali ile birebir eşdeğer olması amacı anketinin Türkçe'ye uyarlanması sürecinde 'Dil Geçerliliği' açısından çeviri basamakları Şekil 1'de gösterilmiştir.,

Türkçe'ye çevirisi yapılan anket herhangi bir dental müdahale yapılmadan önce çalışmaya dahil edilen çocukların yaşı ve cinsiyeti kaydedilerek, ebeveynlerine uygulanmıştır.

Anket soruları (Tablo 1) 3 puanlı skala ile değerlendirilmiştir [0 (hiç), 1 (bazen), 2 (sık sık)]. Rastgele seçilen çocuklardan 30'unun velilerine anket soruları bir hafta sonra tekrar uygulanmıştır. Ankete dahil edilen çocukların dental durumları dmft kriterlerine uygun olarak kaydedilmiştir. Muayene eden hekim bir ağız aynası, dental sond ve kişisel koruyucu ekipman kullanmıştır. ${ }^{9}$

Elde edilen veriler bir Excel (Microsoft 2010) dosyası oluşturularak kaydedilmiş ve kontrolü yapıl-mıştır. İstatistiksel analiz için DRA ölçeğinin güvenilirlik çalışması kapsamında iç tutarlıık Cronbach alfa katsayısı, Test-Test Tekrar tutarlıığı Sınıf içi Korelasyon Katsayısı (SKK) ile değerlendirilmiş-tir. DRA ölçeğinin geçerliliği Toplam puanı ile dmft skoru arasındaki ilişki Spearman korelasyon katsayısı ile incelenmiştir. DRA ölçeğinin cinsiyet değişkeni ile ilgili analizi Mann- Whitney $U$ testi ile değerlendirilmiştir.

\section{BULGULAR}

Çalışmaya dahil edilen 121 çocuğun demografik verileri değerlendirildiğinde 45(\%37.2)'inin kı, 76(\%62.8)'sının erkek, ortalama yaşlarının $3.84 \pm 1.06$, ortalama dmft skorlarının $6.63 \pm 3.92$ olduğu görülmüştür. DRA anketinin mad- 
de analizi için, her maddenin ayrı ayrı düzeltilmiş madde toplam değer korelasyonları hesaplanmıştır. Düzeltilmiş madde toplam korelasyonlarının hesaplanmasında her boyutun kendi toplam puanı kullanılmıştır. Düzeltilmiş madde toplam korelasyonları için 0,245 ile 0,702 arasında değerler almıştır. Düzeltilmiş madde toplam korelasyonlarına ait bulgular Tablo 1.'de gösterilmiştir.

Tablo 1.kaldırılması sonucu elde edilen güvenirlik katsayıları

\begin{tabular}{|c|c|c|c|c|c|}
\hline $\begin{array}{l}\text { DDQ Mad- } \\
\text { deleri }(n=121)\end{array}$ & $\begin{array}{l}\text { Asla } \\
\text { n \% }\end{array}$ & $\begin{array}{l}\text { Bazen } \\
\text { n \% }\end{array}$ & $\begin{array}{l}\text { Siklıkla } \\
\text { n \% }\end{array}$ & $\begin{array}{l}\text { Düzeltilmiş } \\
\text { Madde-Top- } \\
\text { lam korela- } \\
\text { syonu }\end{array}$ & $\begin{array}{l}\text { Madde } \\
\text { silindiğinde } \\
\text { Cronbach alfa } \\
\text { katsayısı }\end{array}$ \\
\hline $\begin{array}{l}\text { 1-Yemek } \\
\text { yerken ağllyor }\end{array}$ & $40(33.1)$ & $53(43.8)$ & $28(23.1)$ & 0.599 & 0.788 \\
\hline $\begin{array}{l}\text { 2-Yemek } \\
\text { yerken dişle- } \\
\text { rini gösteriyor }\end{array}$ & $35(28.9)$ & $54(44.6)$ & $32(26.4)$ & 0.468 & 0.799 \\
\hline $\begin{array}{l}\text { 3-Sevdiği } \\
\text { șeyleri yemek } \\
\text { istemiyor }\end{array}$ & $52(43)$ & $39(32.2)$ & $30(24.8)$ & 0.450 & 0.801 \\
\hline $\begin{array}{l}\text { 4Gece aniden } \\
\text { ağlamaya } \\
\text { basslıyor }\end{array}$ & $56(46.3)$ & $34(28.1)$ & $31(25.6)$ & 0.520 & 0.795 \\
\hline $\begin{array}{l}\text { 5-Tek taraflı } \\
\text { çiğniyor }\end{array}$ & 38 (31.4) & $31(25.6)$ & $52(43)$ & 0.481 & 0.799 \\
\hline $\begin{array}{l}\text { 6-Ciğnemede } \\
\text { problemler } \\
\text { yasilyor }\end{array}$ & $40(33.1)$ & $32(26.4)$ & $49(40.5)$ & 0.702 & 0.775 \\
\hline $\begin{array}{l}\text { 7- On dişleri } \\
\text { yerine arka } \\
\text { dişleri ile } \\
\text { ssiriyor }\end{array}$ & $66(54.5)$ & $22(18.2)$ & 33 (27.3) & 0.284 & 0.818 \\
\hline $\begin{array}{l}\text { 8-Gündüz ku- } \\
\text { lak ağrisI } \\
\text { oluyor }\end{array}$ & 99 (81.8) & $19(15.7)$ & $3(2.5)$ & 0.350 & 0.809 \\
\hline $\begin{array}{l}\text { 9-Gece kulak } \\
\text { agriss oluyor }\end{array}$ & $100(82.6)$ & $14(11.6)$ & $7(5.8)$ & 0.245 & 0.815 \\
\hline $\begin{array}{l}\text { 10-Yemek } \\
\text { yerken kulağı } \\
\text { ağrıyor }\end{array}$ & $105(86.8)$ & $13(10.7)$ & $3(2.5)$ & 0.366 & 0.809 \\
\hline $\begin{array}{l}\text { 11-Alt dișleri } \\
\text { firçalarken so- } \\
\text { run yașıyor }\end{array}$ & 65 (53.7) & $33(27.3)$ & $23(19)$ & 0.558 & 0.791 \\
\hline $\begin{array}{l}\text { 12-Üst dişleri } \\
\text { firçalarken so- } \\
\text { run yaşıyor }\end{array}$ & $62(51.2)$ & $35(28.9)$ & $24(19.8)$ & 0.536 & 0.793 \\
\hline
\end{tabular}

Toplam puanla en yüksek korelasyon gösteren madde "Çiğnemede problem ya-şıyor" ve bunu takiben "Yemek yerken ağlıyor" maddeleri olarak bulunurken en düşük korelasyon gösteren madde ise "Gece kulak ağrısı oluyor" maddesi olarak bulunmuştur, bunu takiben ikinci en az korelasyon gösteren madde, "Gündüz kulak ağrısı oluyor" maddesi olarak bulunmuştur. $\alpha>0.7$ olduğundan tüm maddelerin yüksek güvenirliğe sahip olduğu bulgulanmıştır. Bu değerlendirmeye ait bulgular Tablo 1'de gösterilmiştir.

Cronbach's Alpha ile yapılan testin total güvenilirlik değerlendirmesinde bu ölçek çalışmasının iç tutarlıı̆ı 0.813 değerinde bulunmuştur. Anketin Türkçe versiyonunda iç tutarlılık değeri yüksek bulunmuştur. Test- test tekrar değerlendirilmesinde uyum katsayısı 0,988 oranı ile uyum bulunmuş-tur. Bu sonuç anketin kararlı olduğunu göstermektedir. Bu değerlendirmeye ait bulgular Tablo 2'de gösterilmiştir.
Tablo 2. Test tekrar test uyum değerleri

\begin{tabular}{|c|c|c|c|c|}
\hline & & \multicolumn{2}{|c|}{$95 \%$ GÜVEN ARALIGI } & \\
\hline & $r^{*}$ & Alt Sinir & Üst sin11 & $p$ \\
\hline DRA & 0.988 & 0.975 & 0.994 & 0.000 \\
\hline
\end{tabular}

*r: Sınıf içi korelasyon katsayısı ile değerlendirilen sonuçlar $p<0.001$ için istatis tiksel olarak anlamlı kabul edilmiştir.

DRA ile yaş arasında zıt yönlü bir ilişki olduğu yani artan yaş ile birlikte DRA skorlarında azalma olduğu görülmüştür. Spearman's Korelasyon Katsayısı ile değerlendirilen dmft skoru-DRA anketi ilişkisi değerlendirilmesi sonucunda, DRA ile dmft indeksi arasında istatistiksel olarak anlam bu-lunmasa da ( $p=0.111)$, aynı yönlü pozitif korelasyon olduğu görülmektedir ( $r=0.145)$.Bu değerlen-dirmeye ait bulgular Tablo 3'te gösterilmiştir.

Tablo 3. Dmft skoru ve yaş ile Toplam DRA ilişkisi

\begin{tabular}{|l|l|l|}
\hline & \multicolumn{2}{|c|}{ DDQ } \\
\hline & $\mathrm{r}$ & $\mathrm{p}$ \\
\hline DMFT & 0.145 & 0.111 \\
\hline Yaş & -0.057 & 0.536 \\
\hline
\end{tabular}

*r Spearman's korelasyon katsayısı, ๆ $p<0.001$ için sonuçlar istatistiksel olarak anlamlı kabul edilmiş-tir.

Kız çocuklarla erkek çocukların DRA değerleri arasında anlamlı bir fark bulunamamıştır $(p>0,05)$. DRA toplam değerleri cinsiyete göre değişmemektedir. Bu değerlendirmeye ait bulgular Tablo 4'te gösterilmiştir.

Tablo 4. Cinsiyet ile DRA değerleri ve cinsiyet ilişkisinin değerlendirilmesi

\begin{tabular}{|l|l|l|l|}
\hline & \multicolumn{2}{|c|}{ DDQ } & \\
\hline & Ort \pm SS & $\begin{array}{c}\text { Ortanca } \\
\text { (Min-maks) }\end{array}$ & $\mathrm{p}^{*}$ \\
\hline Cinsiyet & & & \\
\hline Kız çocuk & $7.78 \pm 5.16$ & $7(0-21)$ & \multirow{2}{*}{0.244} \\
\hline Erkek çocuk & $8.67 \pm 5.05$ & $9(0-20)$ & \\
\hline
\end{tabular}

*Mann-Whitney U Testi ile yapılan değerlendirmelerde $\mathrm{p}<0.001$ için sonuçlar istatistiksel olarak an-lamlı kabul edilmiştir. Ort; Ortalama, SS; Standart Sapma, Min; Minimum, Maks; Maksimum

\section{TARTIŞMA}

Dental problemlerin çocukların genel sağlığı ve büyüme eğrileri üzerine olumsuz etkileri vardır. Ya-pılan araştırmalarda stomatognatik sistemin bir parçasının hasarı nedeniyle oluşan ağıı varlığında önemli işlevlerden biri olan yemek yeme ve iletişim kurmanın engellenmesi gibi bireylerin hayat kalitesiyle ilgili temel fonksiyonların etkilendiği gösterilmiştir. Çocukların dental ağrı sonucu bozu-lan yemek yeme alışkanlıkları ve uykubozuklukları nedeniyle, diğer çocuklara göre daha düşük ki-loda oldukları tespit edilmiştir. ${ }^{10}$

Küçük yaş grubundaki çocuklarda öznelliği nedeniyle ağrıyı ölçmek zordur ve genellikle ebeveylerin görüşlerine başvurulur. ${ }^{11}$ Çocuklar ağrıyı algılama, anlama, ha- 
tırlama ve bildirme konusunda zorluk çekerler. Buna ek olarak bilişsel olgunluğa henüz ulaşmadıklarından iletişim yetenekleri de kısıtlı-dır. ${ }^{12}$ Özellikle de 5 yaş altındaki çocuklarda ağrıyı anlamlandırıp, korku kaygı gibi diğer hoş olma-yan durumlardan ayırt etmesi ve bunu doğru bir şekilde aktarabilmesi, her zaman mümkün olama-maktadır. $^{13}$ Bu durumların tamamı ağrı derecelerinin bildirilmesini zorlaştıran durumlardır. Bu ne-denle çok küçük çocuklarda ağrının var olup olmadığını anlamak için davranışlarının gözlenmesine dayanılarak ağrıyı değerlendiren çözüm araçları kullanılması önerilir. ${ }^{14}$

Ayrıca bu araçlar çocukların gösterebileceği ağrı davranışlarına odaklanmamaktadır ve bu yüzden diş ağrısı tanımlanamamaktadır. Bu nedenle DRA (Dental Discomfort Questionnaire) gibi diş ağrısı ile ilişkili davranışlara odaklanan gözlemsel bir aracın kullanılması daha uygundur. DRA'nın veliler tarafından anlaşılması kolaydır ve uygulaması az zaman almaktadır. DRA diş ağrısı ile ilişkili davranışlara odaklanan, okul öncesi çocuklarda diş ağrısını tanımlamak için geliştirilmiş bir davranışsal gözlem aracıdır.15 DRA'nın güvenirliğini incelemek amacıyla psikometrik analizler ya-pılmış ve sonuçlar DRA'nın güvenilir bir ölçek olduğunu göstermiştir. ${ }^{15,16}$

Ölçeklerin hazırlandıkları dilden başka bir dile çevrilmesi ve o dili kullanan ülkede kullanılabilmesi için öncelikle çevrilen ölçeğin güvenilir, geçerli ve aslına uygun olup olmadığını anlamak için uygu-lanan değişik yöntemlere başvurmak gerekir. Çevirisi yapılan ölçütlerin anlam bütünlüğü kadar kül-türel adaptasyonunun da değerlendirilmesi önemlidir. ${ }^{17}$

Bir ölçeğin standardize olabilmesi için aranan temel nitelikler ölçeğin geçerliliği ve güvenilirliğidir. Geçerlilik bir ölçme aracının ölçülmek istenen özellik ya da durumu ölçebilme yeteneğidir. Geçerlilik sınanması için pek çok ölçüt vardır. DRA Türkçe versiyonu ölçeğinin geçerlilik ve güvenilirlik değer-lendirilmesi kapsamında iç tutarlılık Cronbach alfa katsayısı, test- test tekrar tutarlılığı Sınıf içi Ko-relasyon Katsayısı (SKK) yöntemleri kullanılmıştır. Cronbach's Alpha ile yapılan testin total güveni-lirlik değerlendirmesinde değerinin 0,70 veya üzeri olması ölçeğin iç tutarlılığı için gereklidir. Bu ölçek çalışmasında iç tutarlılık 0,813 değerinde bulunmuştur. Dolayısı ile anketin Türkçe versiyo-nunda tatmin edici bir iç tutarlılık değeri bulunmuştur. Bu çalışma sonuçlarına dayanarak DRA'nın genel olarak Türkçe'ye çevirisinin aynı yapıyı ölçtüğünü ve homojen olduğunu söyleyebiliriz. Bu bulgular daha önce yapılan benzer DRA uyarlama çalışması ile paralel sonuçlar göstermektedir. ${ }^{18}$

DRA' nın Türkçe versiyonunun geçerlilik ve güvenirliğinin değerlendirildiği bu çalışmada anket maddelerinin tek tek güvenirlikleri değerlendirildiğinde toplam puanla en yüksek korelasyon gösteren "Çiğnemede problem yaşıyor"ve bunu takiben "Yemek yerken ağlıyor" maddeleri olarak bulunurken en düşük korelasyon gösteren "Gece kulak ağrısı oluyor", bunu takiben ikinci en az ko-relasyon gösteren "Gündüz kulak ağrısı oluyor" maddeleri olmuştur. Bu maddelerin düşük korela-syon göstermelerinin sebebi çocukların diş ağrısı sonucunda oluşan rahatsızlık hissini kulak ağrısı olarak ifade etmeden çok önce çiğneme problemleri olarak ifade etmeleri ve bu sebeple ebeveynlerin vakit kaybetmeden acil müdahale için başvurmalarına bağlı olabileceği düşünülmüştür. Ayrıca bu maddelerin katsayılarının düşük olmasının diğer olası nedenleri; dental ağrının her zaman kulağa yansımaması, çürüğün dental arktaki lokalizasyonu yada çocuğun ağrıyan bölgeyi ayırt edebilecek bilişsel yeteneği ile ilişkili olarak değişebilmesine bağlanabilir.

Bu çalışmanın bir sınırlaması, diş ağrısının ölçülmesinin ebeveyn raporunun esas alınarak yapılması-dır. Bu potansiyel olarak eksik bir referans standardına neden olabilir. Bu yanlılığın en aza indirilme-si amacıyla dentisyondaki çürük oluşumu ve buna bağlı oluşan çürük skorları (dmft) ile DRA skorla-rının arasındaki ilişkinin incelenmesi de çaışmamızda hedeflenmiştir.

DRA orjinal formunda bulunan tüm maddeler Türkçe versiyonunda da birebir aynı şekilde kullanılmıştır. Otuz çocuğun velisine aynı anket formu birer hafta arayla uygulanmıştır. Yapılan test- test tekrar değerlendirilmesinde 0.988 uyum katsayısı ile büyük ölçüde kararlı bir test olduğu bulgu-lanmıştır ( $p<0,001)$.

DRA Türkçe versiyonu incelendiğinde aynı şekilde toplam DRA değerleri ile dmft skoru arasındaki Spearman Korelasyon Katsayısı ile değerlendirilmesi sonucunda aralarındaki ilişki istatistiksel olarak anlamlı bulunmasa da $(p=0,111)$ aynı yönlü (pozitif) bir ilişki yani korelasyon gösterdiği tespit edil-miştir $(r=0,145)$.

DRA Türkçe versiyonunda kız çocuklarla $(7,78 \pm 5,16)$ erkek çocukların $(8,67 \pm 5,05)$ total DRA pu-anları arasında anlamlı bir fark bulunmamıştır ( $p>0,05)$. DRA toplam puanı cinsiyete göre değişme-mektedir. Bu sonuç daha önce yapılan benzer bir çalışma ile uyumlu bulunmuştur. ${ }^{18}$ Anlamlı bir fark-lılığın bulunmamasının nedeninin cinsiyetler arasındaki karşılıklı etkileşime ya da sosyalleşmeye bağ-lı olabileceği bildirilmiştir.18,19

DRA Türkçe versiyonu ile yaş arasında zıt yönlü bir ilişki olduğu yani artan yaş ile birlikte DRA skorlarında azalma olduğu görülmüştür. Bunun sebebinin artan yaş ile birlikte çocukların bilişsel ye-teneklerinin gelişimi, ağrı ifadesini daha net bir şekilde bildirmeleri ve ağrıya bağlı istemsiz davranış-ları baskılama yeteneklerinin gelişimi olabileceği düşünülmüştür.

Türkiye'de çocuklarda süt dişlerinde çürük prevelansı hızı \%33,94 oranındadır. Yapılan başka bir çalışmada 3 yaş grubunda çürüksüz çocuk oranı \%83,7, 4 yaş grubunda $\% 51,4,5$ yaş grubunda $\% 32,1,6$ yaş grubunda ise $\% 42$ olarak bulunmuştur. ${ }^{20,21}$ Mevcut epidemiyolojik veriler göz 
önünde bulundurulduğunda çocuklarda çürük nedeni ile ağrı varlığının tespitinde geçerliliği onaylanmış bir araca gerek duyulduğu görülmüştür.

Çürüğün bu derece yaygın olduğu ülkemizde çürüğün ve çürük ağrısının erken teşhis edilmesi; ağız hijyeni ideal seviyeye yükselmiş genç nesillere ulaşmayı hedeflemekle birlikte tedavi gereksinimlerini azaltarak ve daha kompleks tedavilerin önlenmesini sağlayarak ülke ekonomisine katkıda bulunacak-tır. Ayrıca diş ağrısının küçük çocukların yaşam kalitesine etkisi konusunda ebeveynler, öğretmenler ve sağlık personellerinde farkındalık yaratmaya katkıda bulunabilecektir.

Kültürel olarak uyarlanmış DRA anketinin Türkçe versiyonunun geçerlilik ve güvenirliğinin değerlendirildiği bu çalışmada DRA-Türkçe versiyonu yeterli psikometrik ve ayırıcı özellikleri sağladığı, okul öncesi çocuklarda diş ağrısı değerlendirme aracı olarak geçerli bir anket aracı olarak kullanılabi-leceği sonucuna varılmıştır.

\section{KAYNAKLAR}

1. Bonica JJ. The need of a taxonomy. Pain 1997; 6: 247248.

2. Easton JA, Landgraf JM, Casamassimo PS. Evaluation of a generic quality of life instrument for early childhood caries related pain, Community Dent Oral Epidemiol 2008; 36: 434-440.

3. American Academy of Pediatrics Committee on Psychosocial Aspects of Child and Family Health; Task Force on Pain in Infants, Children, and Adolescents. The assessment and manage-ment of acute pain in infants, children, and adolescents. Pediatrics 2001; 108: 793-797.

4. Lloyd TA. Assessment and control of pain in children. Anaesthesia 1995; 50: 753-755.

5. Versloot J, Veerkamp JS, Hoogstraten J. Dental discomfort questionnaire: assessment of dental discomfort and/or pain in very young children, Community Dent Oral Epidemiol 2006; 34: 47-52.

6. Anelise D, Judith V, Lelesand C R, Costa LR. Screening preschool children with toothache: val-idation of the Brazilian version of the Dental Discomfort Questionnaire. Health Qual Life Out-comes 2014; 12: 30.

7. Fişek N. Psöriasis işlev kaybı indeksi Türkçe geçerlilik ve güvenilirlik çalışması. Deri ve zührevi hastalıkları uzmanlık tezi. İstanbul: İstanbul Üniversitesi; 2009.

8. Petros D, Antonarakos LK. Reliability and validity of the adapted Greek version of scoliosis re-search society- 22 (SRS-22) questionnaire. Scoliosis 2009; 4: 14.

9. Anaise $\mathrm{JZ}$, Measurement of dental caries experience modification of the DMFT index. Commu-nity Dent Oral Epidemiol 1984;12:43-46.

10. Acs G, Lodolini G, Kaminsky S, Cisneros GJ. Effect of nursing caries on body weight in a pe-diatric population. Pediatr Dent 1992; 14: 302-305.

11. Hoffmann DE, Tarzian AJ. The girl who cried pain: a bias against women in the treatment of pain. J Law Med Ethics 2001; 29: 13-27.

12. von Baeyer $C$, Uman LS, Chambers $C T$, Gouthro A. Can we screen young children for their ability to provide accurate self-reports of pain. Pain 2011; 152: 1327-1333.

13. Brand $K$, Thorpe B. Pain assessment in children. Ann Intensive Care 2016; 17: 270-273.

14. Howard R, Carter B, Curry J, Morton N, Rivett K, Rose $\mathrm{M}$, et al. Association of paediatric anesthetists of Great Britain and Ireland: pain assessment. Paediatr Anaesth 2008; 18: 14-18.

15. Versloot J, Veerkamp JS, Hoogstraten J. Dental discomfort questionnaire: assessment of dental discomfort and/or pain in very young children. Community Dent Oral Epidemiol 2006; 34: 47-52.

16. Judith V. Pain in pediatric dentistry, PhD thesis. Pediatric Dentistry, Amsterdam: Faculty of Dentistry ACTA; 2007. 17. Hançer M. Ölçeklerin yazım dilinden başka bir dile çevirileri ve kullanılan değişik yaklaşımlar. Balıkesir Üniversitesi Sosyal Bilimler Enstitüsü Dergisi; 2003.

18. Anelise $D$, Judith V, Cláudio RL, Luciane RC. Screening preschool children with toothache: validation of the Brazilian version of the Dental Discomfort Questionnaire. Health Qual Life Outcomes 2014; 12: 30.

19. Catherine U. Normal Pain Transmission Rev. Pain 2007; 1: 2-6.

20. Kulak-Özkan Y, Ozkan Y, Kazazoğlu E, Arıkan A. Dental caries prevalence, tooth brushing and periodontal status in 150 young people in istanbul: a pilot study. Int Dent $J$ 2001; 51: 451-456.

21. Tulunoğlu Ö, Bodur $H$, Ulusu $T$, Ciğer R, Odabaş $M$. Okul öncesi (3-6 yaş) ve okul çağındaki (7-8 yaş) çocuklarda diş yüzeylerindeki çürük dağııımının ve prevelansının karşılaştırmalı olarak değerlendirilmesi. Gazi Üni Diş Hek Fak Derg 2003; 20: 11-16. 